\title{
Acquired pendular nystagmus in multiple sclerosis: clinical observations and the role of optic neuropathy
}

\author{
Jason J S Barton, Terry A Cox
}

\begin{abstract}
Thirty seven patients with pendular nystagmus due to multiple sclerosis were reviewed. Most developed nystagmus later in a progressive phase of the disease. All had cerebellar signs on examination and evidence of optic neuropathy. MRI in eight patients showed cerebellar or brainstem lesions in seven; the most consistent finding was a lesion in the dorsal pontine tegmentum. Dissociated nystagmus was seen in 18 patients: in these the signs of optic neuropathy were often asymmetric and the severity correlated closely with the side with larger oscillations. This suggests that dissociations in acquired pendular nystagmus may be due to asymmetries in optic neuropathy rather than asymmetries in cerebellar or brainstem disease.
\end{abstract}

(F Neurol Neurosurg Psychiatry 1993;56:262-267)

The site of the lesion responsible for acquired pendular nystagmus is unknown. Some authors have suggested that cerebellar nuclei are involved because it is often associated with other cerebellar signs. ${ }^{1}$ Others have proposed a brainstem site close to the ocular motor nuclei because monocular and dissociated forms of this nystagmus exist. ${ }^{2}$

We have noted that in dissociated nystagmus the eye with a larger amplitude of oscillation always has worse visual acuity. While this may represent degradation of acuity by continuous ocular motion, it may also be that asymmetries in acuity reflect asymmetries in optic neuropathy, since many patients with acquired pendular nystagmus have multiple sclerosis (MS). Asymmetric conduction times in the optic nerve may be relevant to dissociated pendular nystagmus, since a delay in visual feedback has been proposed as a pathophysiological explanation for some types of acquired pendular nystagmus. ${ }^{3}$

We examined the records of patients with acquired pendular nystagmus for cerebellar signs, internuclear ophthalmoplegia, and neuroimaging. As a second part of this study we reviewed other parameters of optic neuropathy for correlations with dissociations in acquired pendular nystagmus.

\section{Methods}

We retrospectively reviewed the records of 39 patients with acquired pendular nystagmus identified from the files of patients seen between 1981-90 at the MS Clinic at the University of British Columbia. Only those with a "clinically definite" or "clinically probable" diagnosis of $\mathrm{MS}^{4}$ and who had been examined by a neuro-ophthalmologist were accepted. Two patients were not studied further because of insufficient data.

Data were taken from the first neuro-ophthalmologic examination noting pendular nystagmus to document the signs most closely associated with its appearance. Visual acuity after refraction was assessed with projected Snellen charts. Colour vision was scored with 16 Ishihara pseudo-isochromatic plates and optic atrophy was graded on fundoscopy on a scale of 0 to $4 .{ }^{5}$ Ocular motility and the amplitude and trajectory of pendular nystagmus were assessed clinically.

Kurtzke global cerebellar disability scores and scores for cerebellar dysarthria and ataxia of the trunk, gait and limbs were taken from the neurological examination carried out closest to the onset of nystagmus. Eight patients also had MRI after the onset of nystagmus.

For the second part of our study we divided our 37 patients into those with symmetric and those with dissociated nystagmus. We examined the data on colour vision, optic atrophy and relative afferent pupillary defects (RAPD) for asymmetry. A difference in colour scores of 2 or more plates and any difference in the score for optic atrophy were taken to indicate asymmetry. Unlike visual acuity, these three indices of optic neuropathy would not be altered by spontaneous nystagmus. The two groups were compared for the presence of asymmetry in these parameters, using a Chi-squared test with continuity correction (Statview II, Abacus Concepts). In those with dissociated nystagmus we examined whether the side with larger amplitude oscillations correlated with the side with more optic neuropathy.

We also reviewed the charts of all other MS patients $(n=260)$ with Kurtzke cerebellar disability scores of 3 or 4 for the most recent data on colour vision, optic atrophy and RAPDs. Only data with a documented concurrent cerebellar disability score of 3 or 4 were used.

\section{Results}

Thirty nine patients were identified from a clinic population of 1855 people with clinically definite or probable MS seen over nine years, yielding a prevalence of 1:47. All 
patients with pendular nystagmus had clinically definite $M S$. The mean time from onset of MS to onset of nystagmus among the 37 patients studied further was $10 \cdot 8$ years (range $=0-35$ years). Only one patient (case 20) presented with oscillopsia as the first symptom of MS. Three developed nystagmus during a relapsing-remitting phase; most developed it during either a relapsing progressive $(n=21)$ or a chronic progressive course $(n=12)$. Only one patient (case 28) was known to have had his nystagmus resolve.

Three patients had monocular pendular nystagmus and 15 had a clinically evident difference in nystagmus amplitude between the two eyes: thus 18 of 37 had clinically dissociated pendular nystagmus (cases 1-18 in table 1).

The effect of convergence was noted in 19 patients. It dampened nystagmus in six, increased it in five, and had no effect in five. Three patients could not converge.

Twenty patients reported oscillopsia. Six of $19(31 \%)$ with symmetric nystagmus had oscillopsia, compared with 14 of $18(77 \%)$ patients with dissociated nystagmus.

\section{CEREBELLAR AND NEURO-OPHTHALMOLOGICAL} SIGNS

Thirty three of 37 patients had positive cerebellar disability scores. Cases 35 and 36 could not be assessed because of severe spastic weakness. Two others had Kurtzke scores of 0 . Case 29 had mild ataxia in the arms, and paraplegia may have masked lower limb cerebellar signs. Case 8 had ocular cerebellar signs and within a month of nystagmus onset developed intention tremor and dysmetria in all limbs.

Most had other ocular motility abnormalities. Abnormal pursuit was most common but may have represented superimposed nystagmus. Fifteen had saccadic dysmetria, six macrosaccadic oscillations, and one ocular flutter. Twenty six had gaze-evoked jerk nystagmus, four had rebound nystagmus, two had convergence-evoked upbeat lid nystagmus and four had convergence-evoked upbeat ocular nystagmus. Internuclear ophthalmoplegia was present in $65 \%$. None had ocular motor nerve palsies and only one patient had palatal myoclonus.

Optic atrophy was present in all except case 20 . This patient presented with oscillopsia and visual evoked potentials showed delayed P100 peaks at 174 and $175 \mathrm{msec}$. Optic atrophy scores were 3 or 4 in at least one eye in $75 \%$.

Nine patients were examined before and after the development of pendular nystagmus. Six had worsening cerebellar scores and two developed internuclear ophthalmoplegias when nystagmus began. Of five patients examined by a neuro-ophthalmologist before nystagmus, three had worsening optic atrophy when nystagmus began.

\section{MRI}

MRI scans in eight patients showed numerous plaques. Infratentorial lesions were seen in seven. In six, lesions were seen in both the cerebellum and brainstem (table 2); brain-

Table 1 Pendular nystagmus, oscillopsia, and tests of vision.

\begin{tabular}{|c|c|c|c|c|c|c|c|c|c|c|}
\hline Case & $\begin{array}{l}\text { Side of } \\
\text { nystagmus }\end{array}$ & Trajectory & Oscillopsia & $\begin{array}{l}\text { Acuity } \\
R\end{array}$ & & $\begin{array}{l}\text { Colou } \\
R\end{array}$ & $n^{*}$ & $\begin{array}{l}O p \\
R\end{array}$ & hyt & $R A P D+\dagger$ \\
\hline $\begin{array}{l}1 \\
2 \\
3 \\
4 \\
5 \\
6 \\
7 \\
8 \\
9 \\
10 \\
11 \\
12 \\
13 \\
14 \\
15 \\
16 \\
17 \\
18 \\
19 \\
20 \\
21 \\
22 \\
23 \\
24 \\
25 \\
26 \\
27 \\
28 \\
29 \\
30 \\
31 \\
32 \\
33 \\
34 \\
35 \\
36 \\
37\end{array}$ & $\begin{array}{l}L \\
R \\
R \\
L>R \\
L>R \\
L>R \\
L>R \\
L>R \\
L>R \\
L>R \\
L>R \\
L>R \\
R>L \\
R>L \\
R>L \\
R>L \\
R>L \\
R>L \\
R=L \\
R=L \\
R=L \\
R=L \\
R=L \\
R=L \\
R=L \\
R=L \\
R=L \\
R=L \\
R=L \\
R=L \\
R=L \\
R=L \\
R=L \\
R=L \\
R=L \\
R=L \\
R=L\end{array}$ & $\begin{array}{l}\text { vertical } \\
\text { vertical } \\
\text { vertical } \\
\text { vertical } \\
\text { vertical } \\
\text { vertical } \\
\text { vertical } \\
\text { circular } \\
\text { circular } \\
\text { circular } \\
\text { circular } \\
\text { horizontal } \\
\text { vertical } \\
\text { vertical } \\
\text { circular } \\
\text { elliptical } \\
\text { horizontal } \\
? \\
\text { vertical } \\
\text { vertical } \\
\text { circular } \\
\text { circular } \\
\text { circular } \\
\text { elliptical } \\
\text { elliptical } \\
\text { ellitpical } \\
\text { elliptical } \\
\text { horizontal } \\
\text { horizontal } \\
\text { horizontal } \\
\text { horizontal } \\
\text { horizontal } \\
? \\
? \\
? \\
? \\
?\end{array}$ & $\begin{array}{l}+ \\
- \\
+ \\
+ \\
+ \\
+ \\
+ \\
+ \\
+ \\
+ \\
+ \\
+ \\
+ \\
+ \\
+ \\
+ \\
+ \\
+ \\
+ \\
- \\
+ \\
+ \\
+ \\
+ \\
+ \\
+ \\
+ \\
+ \\
- \\
- \\
- \\
- \\
+\end{array}$ & $\begin{array}{l}80 \\
80 \\
200 \\
60 \\
100 \\
200 \\
25 \\
25 \\
\text { cf4' } \\
80 \\
25 \\
60 \\
\text { cf } \\
40 \\
400 \\
300 \\
30 \\
? \\
60 \\
20 \\
400 \\
<400 \\
\text { cf } \\
200 \\
200 \\
400 \\
200 \\
200 \\
400 \\
100 \\
400 \\
25 \\
30 \\
50 \\
200 \\
\text { cf } \\
20\end{array}$ & $\begin{array}{l}\text { cf } \\
60 \\
25 \\
400 \\
200 \\
200 \\
80 \\
70 \\
\text { cf4' } \\
100 \\
200 \\
80 \\
50 \\
25 \\
70 \\
300 \\
30 \\
? \\
60 \\
20 \\
400 \\
<400 \\
\text { cf } \\
400 \\
200 \\
400 \\
200 \\
200 \\
400 \\
100 \\
400 \\
20 \\
30 \\
50 \\
200 \\
400 \\
20\end{array}$ & $\begin{array}{l}8 \\
4 \\
1 \\
? \\
11 \cdot 5 \\
14 \\
11 \\
14 \\
6 \\
8 \cdot 5 \\
? \\
8 \\
0 \\
10 \\
0 \\
5 \\
6 \\
? \\
7 \\
16 \\
1 \\
0 \\
0 \\
? \\
? \\
0 \\
? \\
8 \\
0 \\
5 \cdot 5 \\
0 \\
16 \\
? \\
11 \\
0 \\
0 \\
?\end{array}$ & $\begin{array}{l}0 \\
7 \cdot 5 \\
13 \cdot 5 \\
? \\
6 \cdot 5 \\
15 \\
0 \\
12 \\
0 \\
7 \\
? \\
9 \\
12 \\
10 \\
1 \\
3 \\
5 \\
? \\
6 \\
16 \\
1 \\
0 \\
3 \\
? \\
? \\
0 \\
? \\
9 \\
0 \\
6 \\
0 \\
16 \\
? \\
9 \\
0 \\
0 \\
?\end{array}$ & $\begin{array}{l}2 \\
3 \\
3 \\
0 \\
4 \\
3 \\
2 \\
2 \\
4 \\
2 \\
3 \\
2 \\
3 \\
2 \\
3 \\
3 \\
1 \\
2 \\
3 \\
0 \\
3 \\
2 \\
4 \\
2 \\
2 \\
4 \\
4 \\
4 \\
3 \\
4 \\
1 \\
3 \\
3 \\
4 \\
3 \\
3 \\
2 \\
3\end{array}$ & $\begin{array}{l}3 \\
3 \\
0 \\
2 \\
4 \\
3 \\
3 \\
3 \\
4 \\
3 \\
4 \\
3 \\
3 \\
1 \\
2 \\
2 \\
1 \\
0 \\
3 \\
0 \\
3 \\
2 \\
3 \\
2 \\
3 \\
4 \\
3 \\
2 \\
4 \\
4 \\
1 \\
3 \\
3 \\
3 \\
3 \\
3 \\
2 \\
0\end{array}$ & $\begin{array}{l}- \\
\bar{R} \\
- \\
- \\
\bar{L} \\
\mathbf{L} \\
\mathbf{L} \\
- \\
- \\
- \\
- \\
- \\
\overline{\mathbf{R}} \\
- \\
- \\
- \\
- \\
- \\
- \\
- \\
- \\
- \\
- \\
- \\
- \\
- \\
- \\
- \\
- \\
- \\
- \\
- \\
- \\
- \\
-\end{array}$ \\
\hline
\end{tabular}


Table 2 Infratentorial lesions in pendular nystagmus on MRI scans.

\begin{tabular}{|c|c|c|c|c|c|}
\hline \multirow[b]{2}{*}{ Case } & \multirow{2}{*}{$\begin{array}{l}\text { Duration of } \\
\text { nystagmus } \\
\text { before MRI }\end{array}$} & \multicolumn{2}{|l|}{ Brainstem } & \multicolumn{2}{|l|}{ Cerebellum } \\
\hline & & medial & lateral & lobe & peduncle \\
\hline 1 & 36 months & $\begin{array}{l}\text { Dorsal pontine } \\
\text { tegmentum }\end{array}$ & $\begin{array}{l}\text { Midbrain, } \\
\text { pons }\end{array}$ & $\begin{array}{l}\text { superior vermis, } \\
\text { Right hemisphere }\end{array}$ & Right \\
\hline 11 & 12 months & $\begin{array}{l}\text { Dorsal pontine } \\
\text { tegmentum }\end{array}$ & $\begin{array}{l}\text { Cerebral } \\
\text { peduncles }\end{array}$ & $\begin{array}{l}\text { hemispheres, } \\
\text { Right > Left }\end{array}$ & 0 \\
\hline 20 & 8 months & $\begin{array}{l}\text { Dorsal pontine } \\
\text { tegmentum }\end{array}$ & 0 & 0 & 0 \\
\hline 21 & 8 months & $\begin{array}{l}\text { Dorsal pontine } \\
\text { tegmentum }\end{array}$ & $\begin{array}{l}\text { Midbrain, } \\
\text { pons }\end{array}$ & 0 & Right, Left \\
\hline $\begin{array}{l}25 \\
27\end{array}$ & $\begin{array}{l}1 \text { month } \\
1 \text { month }\end{array}$ & $\begin{array}{l}0 \\
\text { Midbrain, } \\
\text { pons }\end{array}$ & Midbrain, & $\begin{array}{l}0 \\
\text { Superior vermis, } \\
\text { hemispheres }\end{array}$ & $\begin{array}{l}0 \\
\text { Right, Left }\end{array}$ \\
\hline 37 & 3 months & $\begin{array}{l}\text { Dorsal pontine } \\
\text { tegmentum }\end{array}$ & $\begin{array}{l}\text { Pons, } \\
\text { Left > Right }\end{array}$ & Hemispheres & Left \\
\hline
\end{tabular}

stem lesions were in the dorsal pontine tegmentum and the anterolateral pons or midbrain simultaneously in all six. Case 20, the patient who presented with pendular nystagmus as her first sign of MS, had a single lesion in the dorsal pontine tegmentum (fig 1).

VISUAL FUNCTION IN SYMMETRIC VS DISSOCIATED PENDULAR NYSTAGMUS

Most patients had significantly reduced visual acuity, especially those with symmetric nystagmus (table 1); however, pendular nystagmus was not incompatible with good acuity (for example, cases $17,20,32,37$ ). Only three of 19 with symmetric nystagmus had asymmetric acuity; 16 of 18 with dissociated nystagmus had asymmetric acuity, often pronounced. Moreover, the eye with worse acuity always had larger oscillations. Since this reduced acuity may have resulted from the continuous motion of the eye, we examined three other indices of optic neuropathy in these patients (fig 2).

Two of 14 with symmetric nystagmus had asymmetric colour vision, compared with nine of 15 with dissociated nystagmus. Eight of these nine had worse colour vision in the eye with larger oscillations.

Six of $19(32 \%)$ with symmetric nystagmus

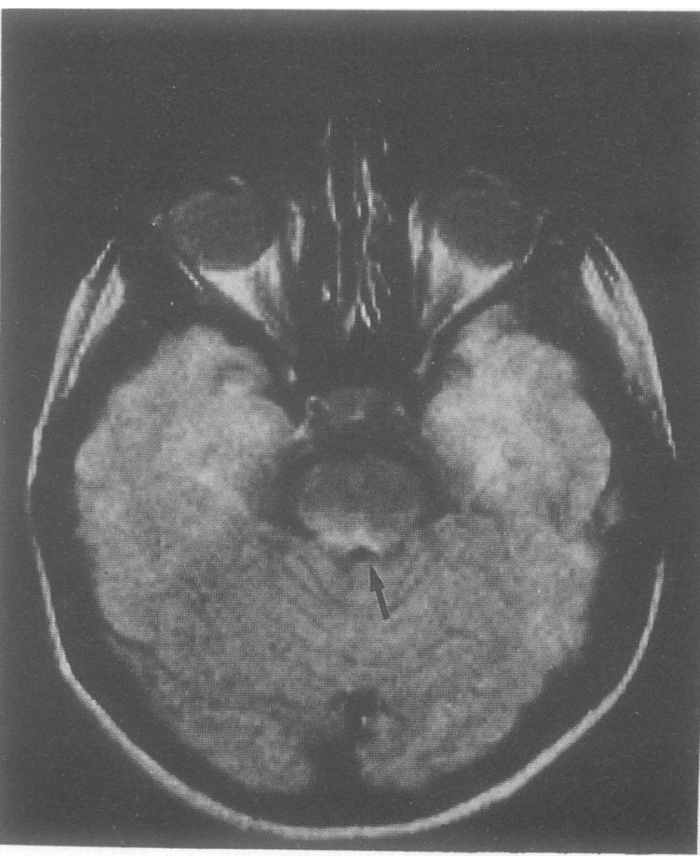

Figure 1 T1-weighted MRI of patients $20(A)$ and $21(B)$. Arrows indicate increased signal in dorsal pontine tegmentum. had asymmetric optic atrophy, compared with 12 of $18(66 \%)$ with dissociated nystagmus. All 12 had greater optic atrophy in the eye with larger oscillations.

Only five had RAPDs. All had dissociated nystagmus and all had the RAPD in the eye with larger oscillations.

In contrast, asymmetry in cerebellar signs or internuclear ophthalmoplegia did not correlate with either the presence of asymmetry or the side of asymmetry of pendular nystagmus (fig 2). Two had more severe internuclear ophthalmoplegia on the side with more nystagmus and five had more severe ophthalmoplegia on the other side.

\section{COMPARISON WITH PATIENTS WITH}

CEREBELLAR SIGNS BUT NO PENDULAR NYSTAGMUS

In patients with cerebellar signs but no pendular nystagmus $29 \%$ had no or minimal optic atrophy (scores of 0 or 1), compared with $8 \%$ of the 37 patients with pendular nystagmus (fig 3).

A total of $33 \%$ of the cerebellar group without nystagmus had asymmetric optic atrophy and $11 \%$ had an RAPD. Similarly, $33 \%$ of patients with symmetric nystagmus had asymmetric atrophy and none had an RAPD. In contrast, $66 \%$ of those with dissociated nystagmus had asymmetric atrophy and $28 \%$ had an RAPD. Thus patients with dissociated nystagmus have a higher incidence of asymmetry in indices of optic neuropathy compared with both cerebellar controls and those with symmetric pendular nystagmus (fig 4).

\section{Discussion}

Aschoff et al described 29 cases of acquired pendular nystagmus: $56 \%$ had dissociated nystagmus, compared with $45 \%$ in our series. ${ }^{1}$ They noted an association with other cerebellar signs and proposed that lesions of

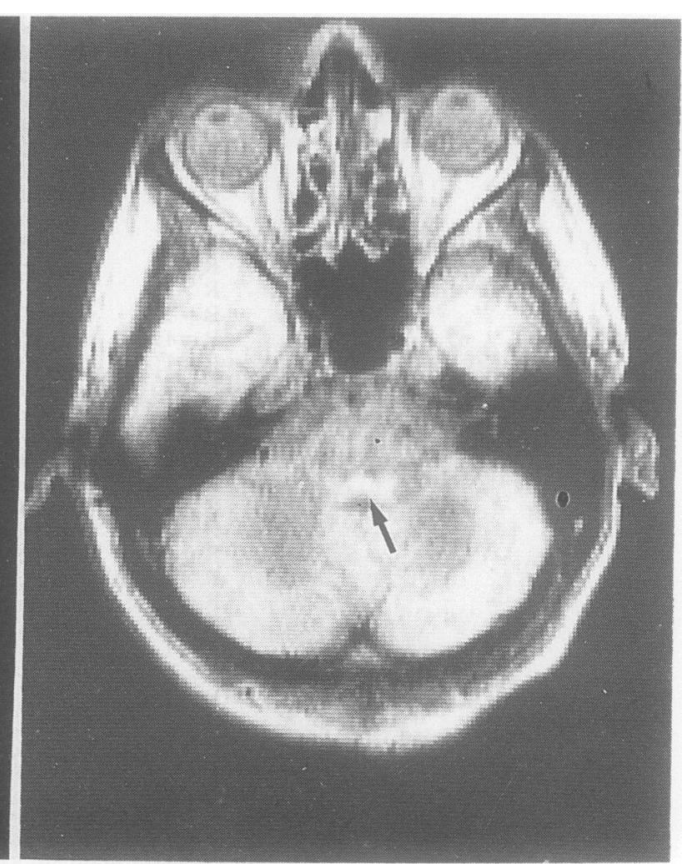


Figure 2 Frequency of asymmetries in vision, ataxia and internuclear ophthalmoplegia (INO) in patients with symmetric versus dissociated pendular nystagmus.
Figure 3 Severity of optic atrophy graded from 0 to 4 ( 0 none, 4 most severe) in patients with pendular nystagmus and patients with cerebellar signs but without pendular nystagmus. Data taken from the worst eye when atrophy was asymmetric. Patients with pendular nystagmus tend to have a greater degree of optic atrophy $(p<0.001$, contingency table analysis).

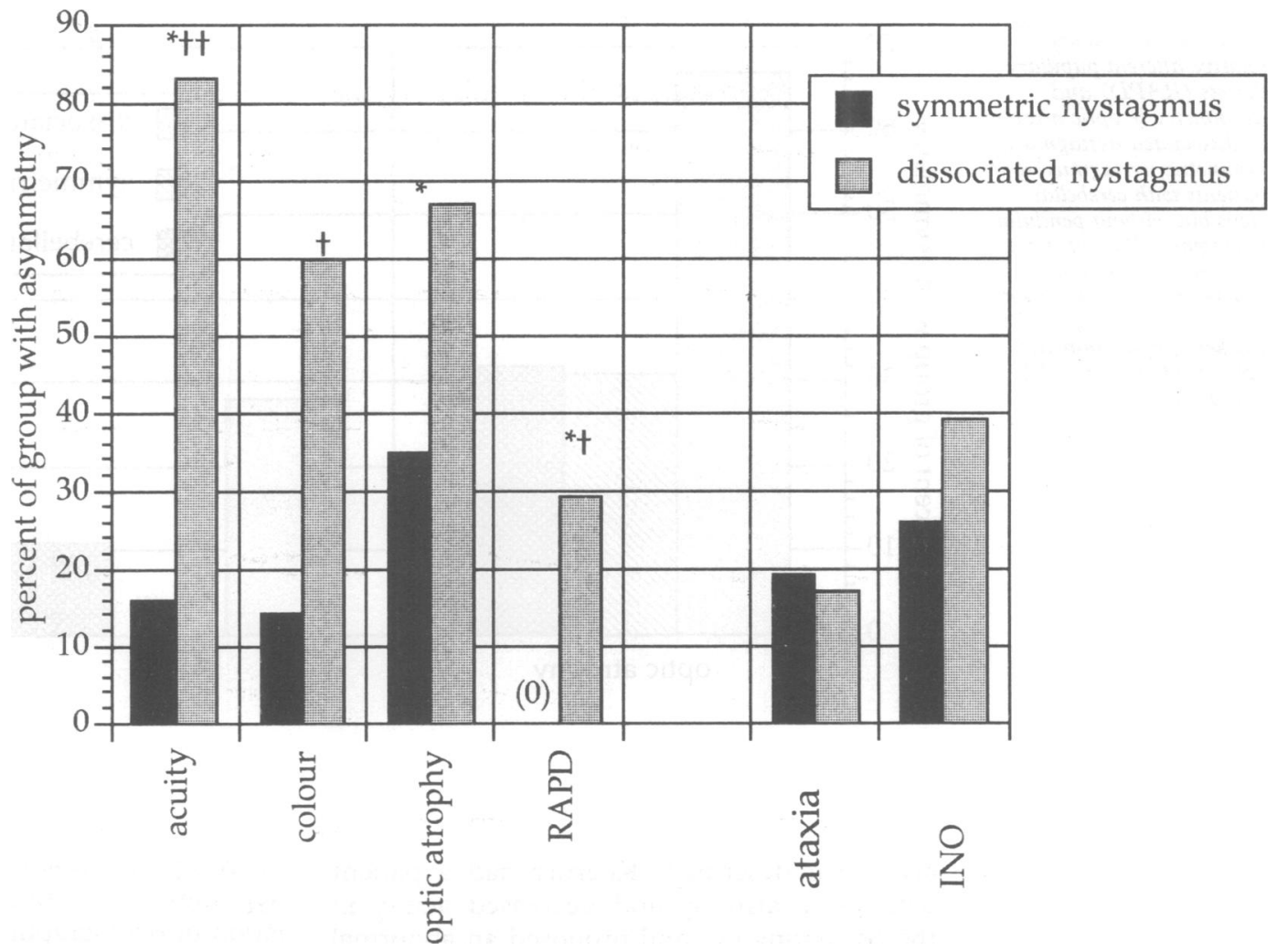

* side with more impairment always the side with larger oscillations.

+ significant at $p<0.05$

$t+$ significant at $p<0.01$

the cerebellar nuclei or their connections were responsible. Nashold et al had also created pendular oscillations by stimulating medial cerebellar structures. ${ }^{6}$ In contrast, Gresty et al studied 16 patients, a third of whom did not have MS. ${ }^{2}$ Less than half had

cerebellar signs, but many had skew deviations and internuclear ophthalmoplegia, suggesting a brainstem site. Dissociated forms were attributed to lesions close to individual ocular motor nuclei. Cases of monocular acquired pendular nystagmus in MS have

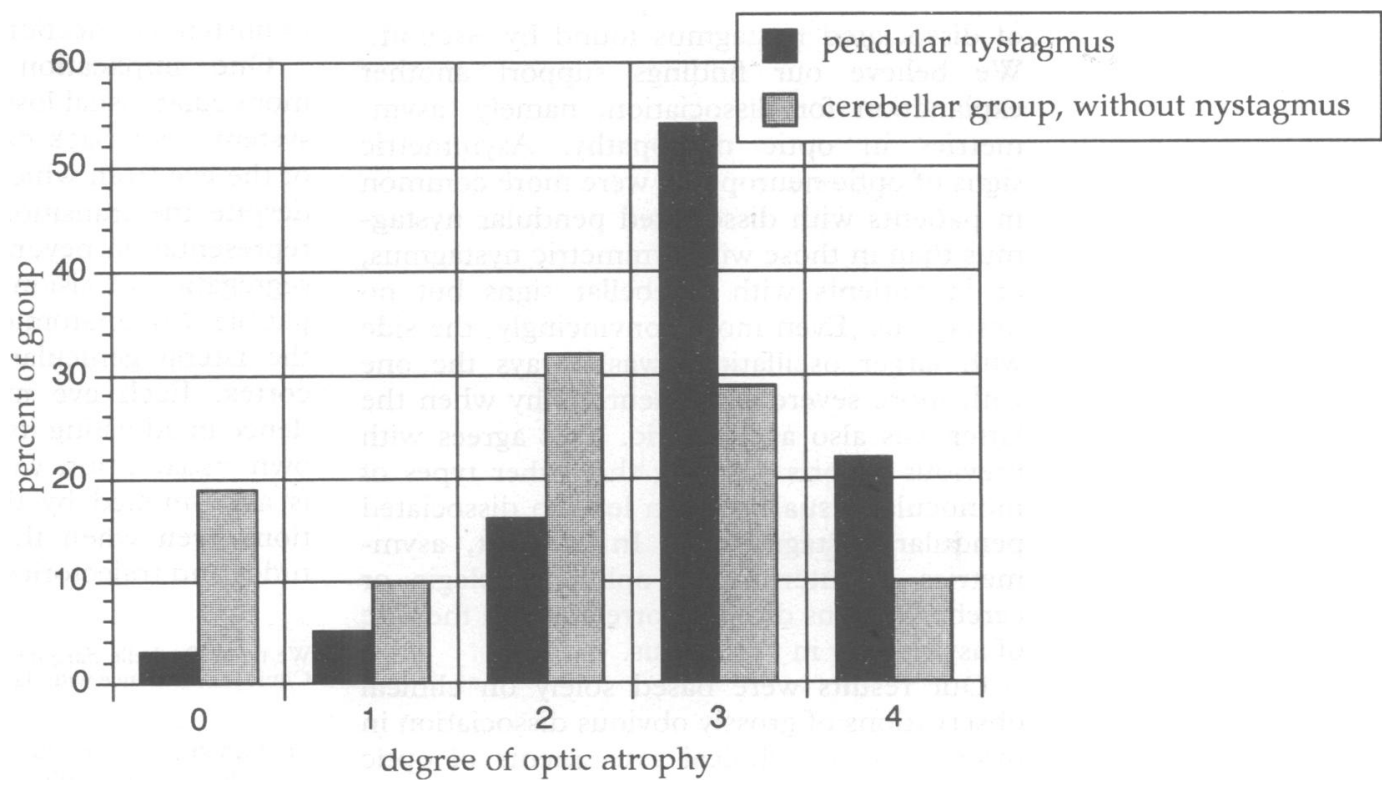


Figure 4 Frequency of relative afferent pupillary defects (RAPD) and asymmetry in optic atrophy in dissociated nystagmus, symmetric nystagmus, and patients with cerebellar signs but without pendular nystagmus. Patients with asymmetric nystagmus differed significantly from the cerebellar group in the frequency of asymmetric optic atrophy $(p<0.01$, chi square).

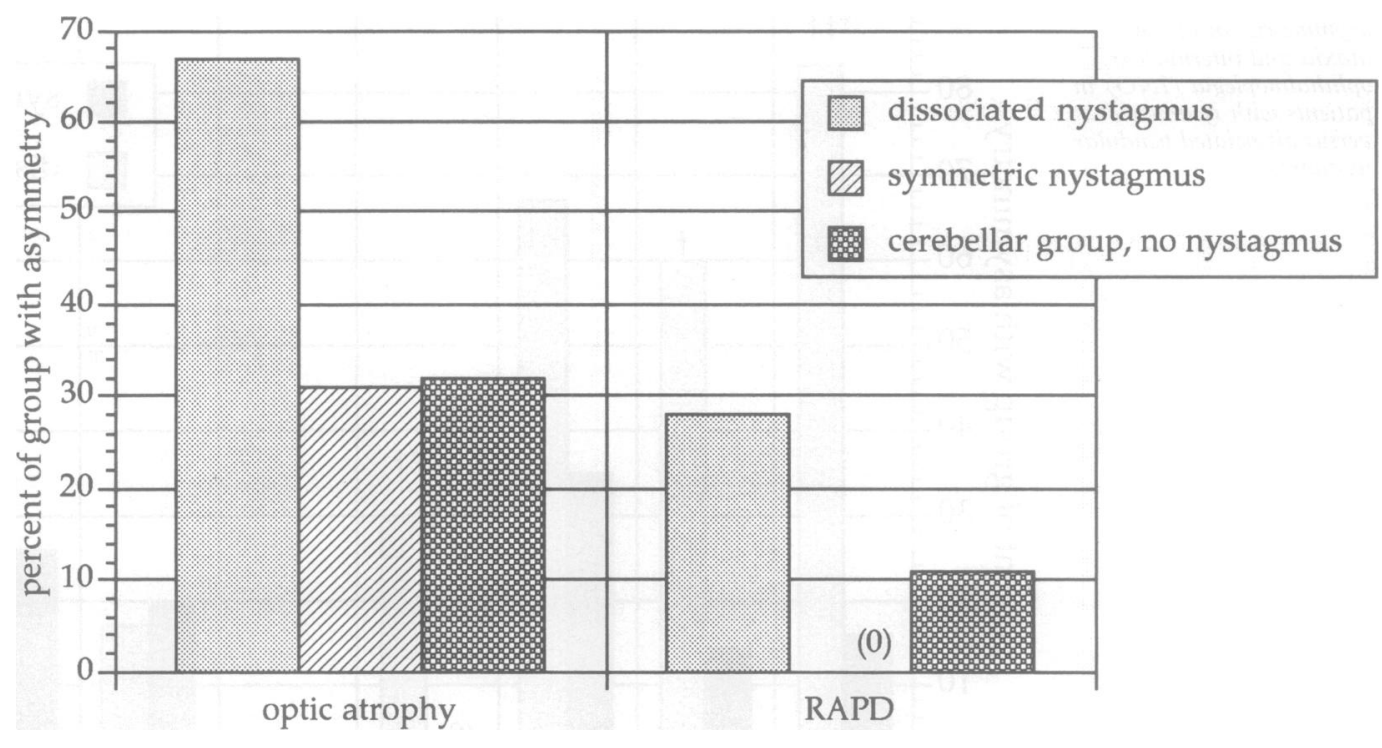

also been described. Koerner had a patient with optic atrophy and decreased acuity in the oscillating eye and proposed an abnormal sensory feedback loop, ${ }^{7}$ but Castaigne et al did not find clinical optic neuropathy in their case and attributed reduced acuity to motion degradation. $^{8}$

Our study confirms a strong and universal association between. acquired pendular nystagmus and cerebellar signs, whereas internuclear ophthalmoplegia was seen in only $65 \%$. Nevertheless, MRI showed that the most consistent findings were lesions in the dorsal pontine tegmentum. This is of interest since the central tegmental tract might be affected by such lesions. Lesions of this tract may be one cause of palatal myoclonus, which can be associated with pendular nystagmus. ${ }^{9}$

Gresty et $a l^{2}$ proposed that dissociated nystagmus occurred when brainstem lesions affected the ocular motor nuclei serving each eye asymmetrically. Such an explanation does not easily account for the phase-locked nature of dissociated nystagmus found by Aschoff. ${ }^{1}$ We believe our findings support another explanation for dissociation, namely, asymmetries in optic neuropathy. Asymmetric signs of optic neuropathy were more common in patients with dissociated pendular nystagmus than in those with symmetric nystagmus, or in patients with cerebellar signs but no nystagmus. Even more convincingly, the side with larger oscillations was always the one with more severe optic neuropathy when the latter was also asymmetric. This agrees with previous reports showing that other types of monocular visual loss can lead to dissociated pendular nystagmus. ${ }^{10-13}$ In contrast, asymmetries in internuclear ophthalmoplegia or cerebellar signs did not correlate with the side of asymmetry in nystagmus.

Our results were based solely on clinical observations of grossly obvious dissociation in nystagmus and clinical assessments of optic neuropathy. These assessments were made by neuro-ophthalmologists unaware of our hypothesis at the time of assessment. A correlation of oculographic measures of nystagmus amplitude and objective tests of visual function such as pupillometry or visual evoked potentials would be useful in confirming our findings, but the latter may be difficult to perform in subjects whose eyes are continually moving. Nevertheless, our findings suggest that even at a gross observational level a correlation exists with optic neuropathy.

The appearance therefore of acquired pendular nystagmus may reflect the expression of two lesions. It is not clear, however, whether two lesions are necessary or whether cerebellar dysfunction is the sole necessary condition and optic neuropathy merely influences its expression. Slowed conduction in optic neuropathy, even in the presence of good acuity, could create abnormal feedback to a visual fixation system. ${ }^{7}$ The cerebellum may compensate for oscillations due to delays in this visual fixation feedback loop unless it or its brainstem connections are affected.

One implication of our findings and monocular visual loss studies is that the visual system feeds back data to the motor systems of the eye from which the image was derived, despite the transition to binocular hemifield representation beyond the optic chiasm. This segregation of vision by eye of origin is compatible with anatomical data on segregation in the lateral geniculate nucleus and calcarine cortex. Each eye maintains some independence in adjusting its position according to its own visual input, yet some conjugate control is also implied by the phase-lock of oscillations even when they have different amplitudes and trajectories. ${ }^{1}$

We thank Rochelle Farquhar RN and Sandy Fraser of the MS Clinic for assistance with data compilation.

1 Aschoff JC, Conrad B, Kornhuber HH. Acquired pendular nystagmus with oscillopsia in multiple sclerosis: a sign of cerebellar nuclei disease. $\mathcal{f}$ Neurol Neurosurg 
Psychiatry 1974;37:570-7.

2 Gresty MA Ell JJ, Findley LJ. Acquired pendular nystagmus: its characteristics, localizing value and pathophysiology. $₹$ Neurol Neurosurg Psychiatry 1982;45:431-9.

3 Sharpe JA, Hoyt WF, Rosenberg MA. Convergenceevoked nystagmus: congenital and acquired forms. Arch Neurol 1975;32:191-4.

4 Posner CM, Paty DW, Scheinberg L, McDonald WI, Ebers GC, ed. The diagnosis of multiple sclenosis. New York: Thieme-Stratton, 1984

5 Cox TA. Relative afferent pupillary defects in multiple sclerosis. Can 7 Ophthalmol 1989;24:207-10.

6 Nashold BS, Slaughter DG, Gills JP. Ocular reactions in man from deep cerebellar stimulation and lesions. Arch Ophthalmol 1969;81:538-43.

7 Koerner F. Acquired and congenital monocular pendular nystagmus. A comparative electronystagmographic nystagmus. A comparative electronystagmographic
study of two cases. Albrecht $v$ Graefes Arch Klin Exp Ophthalmol 1975;197:165-175.
8 Castaigne P, Chain F, Pierrot-Deseilligny C, Larmande P. Le nystagmus de circumduction monoculaire. Rev Neurol (Paris) 1979;135:51-57.

9 Nakada T, Kwee IL. Oculopalatal myoclonus. Brain 1986;109:431-41.

10 Smith JL, Flynn JT, Spiro HJ. Monocular vertical oscillations of amblyopia: the Heimann-Bielschowsky phenomenon. 7 Clin Neuro-ophthalmol 1982;2:85-91.

11 Yee RD, Jelks GW, Baloh RW, Honrubia V. Uniocular nystagmus in monocular visual loss. Ophthalmol 1979; 86:511-18.

12 Stangler-Zuschrott E. Störungen der Okulomotorik während Punktfixation des führenden Auges bei einseitiger Deprivationsamblyopie, Schielamblyopie und einseitigem Organschaden. Klin Mbl Augenheilk 1987;191: 403-8.

13 Leigh RJ, Thurston SE, Tomsak RL, Grossman GE, Lanska DL. Effect of monocular visual loss upon stability of gaze. Invest Ophthalmol Vis Sci 1989;30:288-92. 